\title{
Microstructural Evolution and Mechanical Behavior of Thermally Aged Cast Duplex Stainless Steel
}

\author{
Zhenhua $\mathrm{Li}^{1,2}{ }^{1}$, Ying $\mathrm{Hu}^{2}$, Tao Chen ${ }^{1}$, Xinyu Wang ${ }^{2}$, Pan Liu ${ }^{1}$ and Yonghao $\mathrm{Lu}^{2, *}$ \\ 1 State Key Laboratory of Nuclear Power Safety Monitoring Technology and Equipment, \\ China Nuclear Power Engineering Co., Ltd., Shenzhen 518172, China; zhenhuali_ustb@163.com (Z.L.); \\ chent2@cgnpc.com.cn (T.C.); liup@cgnpc.com.cn (P.L.) \\ 2 National Center for Materials Service Safety, University of Science and Technology Beijing, \\ Beijing 100083, China; huying2017@aliyun.com (Y.H.); wangxinyu-010@163.com (X.W.) \\ * Correspondence: lu_yonghao@mater.ustb.edu.cn
}

Received: 25 November 2020; Accepted: 8 December 2020; Published: 10 December 2020

\begin{abstract}
The microstructural evolution and mechanical behavior of cast duplex stainless steels (CDSSs) at $400{ }^{\circ} \mathrm{C}$ for different thermal aging times were investigated by transmission electron microscope (TEM) and small punch test (SPT). The results showed that the spinodal decomposition in ferrite was the main reason for the decrease in toughness, and G-phase did not play an important role in the embrittlement process. The change of membrane stretching zone $\left(\mathrm{W}_{\mathrm{m}}\right)$ played an important role in the SPT load-displacement curve before and after thermal aging. During the deformation process of $\mathrm{W}_{\mathrm{m}}$ in the SPT, for thermal aging for 10,000 h, some completely curved slip bands were generated inside the ferrite phase, which had no contact with the $\delta / \gamma$ phase interface and belonged to the slip bands produced by the independent deformation of ferrite. The combined effect of the curved slip bands and stress concentration led to the initiation of obvious micro-cracks at the $\delta / \gamma$ phase interface. The micro-cracks propagated along the ferrite phase curved slip bands, and eventually penetrated the entire hardened ferrite phase.
\end{abstract}

Keywords: thermal aging; G-phase; small punch test; cast duplex stainless steel; mechanical behavior

\section{Introduction}

Cast duplex stainless steel (CDSS) is widely used in the primary coolant pipe of a pressurized water reactor (PWR) nuclear power plant because of its excellent comprehensive properties [1-5]. However, CDSS is prone to phase decomposition when it is in the range of $280-500{ }^{\circ} \mathrm{C}$ for a long time, resulting in thermal aging brittleness, which reduces the plasticity and toughness of the material and increases the hardness and brittleness, thereby increasing the possibility of a sudden failure of components and affecting the safe operation of nuclear power plants [6-10].

It has been reported that the increase of brittleness in CDSS during thermal aging is mainly due to the generation of the Fe-rich $\alpha$ phase and the Cr-rich $\alpha^{\prime}$ phase, and the precipitation of the G-phase for long-term thermal aging [11-15]. Chandra et al. [16] found that the "speckle" feature appeared in ferrite after thermal aging by transmission electron microscope (TEM), which has been confirmed by many studies as the characteristic of spinodal decomposition in ferrite, and the strength of the speckle feature can also represent the degree of spinodal decomposition in ferrite $[15,17]$. Pareige et al. [18] studied the kinetics of spinodal decomposition and G-phase precipitation in a ferrite of duplex stainless steel after thermal aging treatment by using atom probe tomography (APT) technology, and proved the formation mechanism of G-phase.

For the CDSS after thermal aging, due to the spinodal decomposition in the ferrite phase and the generation of the G-phase, it is difficult for the hardened ferrite to deform and slip during the 
deformation process, which reduces the deformation coordination between the austenite and ferrite phases, resulting in the stress concentration at the interface of the austenite and hardened ferrite phases, which ultimately leads to the increase in brittleness and the decrease in mechanical properties. Therefore, it is particularly important to study the mechanical behavior of each phase after thermal aging. At present, many studies have been used to characterize the brittleness and deformation behavior of thermal aging through traditional tensile and impact tests $[19,20]$. The results show that the appearance of spinodal decomposition and G-phase leads to the hardening of ferrite, and thus increases the brittleness sensitivity of materials. However, due to the large size of the experimental materials required by traditional methods, the utilization rate of materials is not high and it is difficult to test and analyze the equipment components in service, so a more convenient and material-saving method is needed to detect the change in service performance of materials [21].

This study focuses on the microstructural characteristics of CDSS at $400{ }^{\circ} \mathrm{C}$ under different thermal aging times, and systematically observes the spinodal decomposition and second phase precipitation behavior in ferrite, revealing and summarizing the evolution of CDSS microstructure before and after the thermal aging process. It then analyzes and discusses the changes in microhardness properties. Moreover, the deformation behavior and fracture mechanism of CDSS before and after thermal aging are characterized and analyzed by means of small punch test (SPT).

\section{Material and Experimental Procedure}

\subsection{Test Material}

The materials investigated in this study were CDSS Z3CN20-09M, which was obtained from a new component of the primary circuit piping. The chemical composition (wt.\%) of the Z3CN20-09M material used in this study was as follows: $20.16 \mathrm{Cr}, 8.93 \mathrm{Ni}, 0.02 \mathrm{C}, 1.07 \mathrm{Si}, 1.02 \mathrm{Mn}, 0.063 \mathrm{Cu}, 0.026 \mathrm{Co}$, $0.22 \mathrm{Mo}$, Balance Fe. The test materials were then subjected to a thermal aging treatment at $400{ }^{\circ} \mathrm{C}$, and the thermal aging times were 400,1000, 5000 and 10,000 h, respectively. According to the Arrhenius equation as shown in Equation (1), the aging effect at $400{ }^{\circ} \mathrm{C}$ for $10,000 \mathrm{~h}$ was equivalent to 36.4 years at the service temperature (i.e., $290^{\circ} \mathrm{C}$ ) [22].

$$
\frac{t_{1}}{t_{2}}=\exp \left[\frac{Q}{R}\left(\frac{1}{T_{1}}-\frac{1}{T_{2}}\right)\right]
$$

where $t_{1}$ and $t_{2}$ are the service times at the temperatures $T_{1}$ and $T_{2}$, respectively, $Q$ is the Arrhenius activation energy, and $R$ is the gas constant.

\subsection{Test Conditions and Methods}

SPT was a semi non-destructive test method. It had been widely considered as an effective test method to obtain the performance data of related materials by using small specimen sizes. Figure 1 is the schematic diagram of the SPT device. The test device was divided into two parts, and the upper and lower parts of the device were fixed by screws. The SPT specimens were discs with a diameter of $10 \mathrm{~mm}$ and a thickness of $0.5 \pm 0.02 \mathrm{~mm}$. There were three parallel specimens in each thermal aging state. It can be seen that the universal test machine was used to load a $2.5 \mathrm{~mm}$ diameter stainless steel punch into the upper part (the load was set to $10 \mathrm{kN}$ ), so as to push the specimen deformation to the lower part. The load-displacement curves of each SPT were recorded by the computer of the universal testing machine. During the SPT, the preset loading speed was $0.2 \mathrm{~mm} / \mathrm{min}$. All SPTs were performed at room temperature. When the loading dropped to $80 \%$ of the maximum load in the test, it was considered that a significant fracture occurred in the SPT specimen, and the material failed.

The hardness of the ferrite and austenite phases was studied using a Vickers hardness tester under a load of $10 \mathrm{~g}$. Large grain sizes were selected as much as possible, and the indentation should be close to the grain center, so as to avoid the influence of adjacent grains on the measurement 
results. Eight measurements were made for each test and the hardness value was the average of the eight measurements.

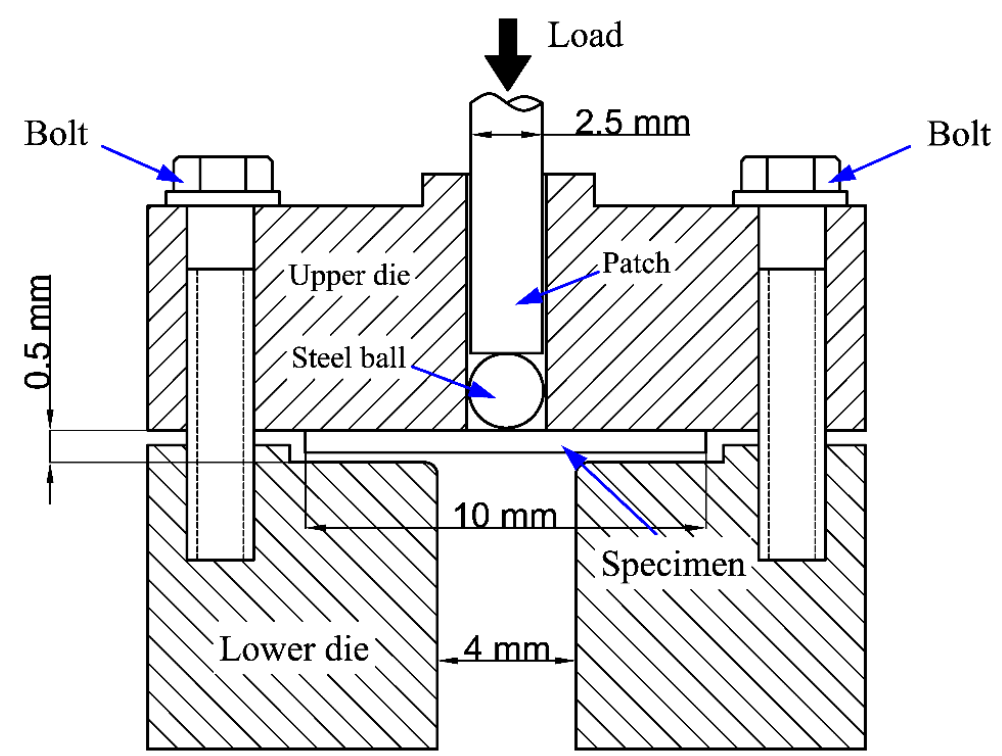

Figure 1. The schematic of the small punch test (SPT) device.

\subsection{Microstructural Characterization}

In order to clearly show the phase interface, the metallographic sample was polished and then electrolytic etched with $10 \%$ oxalic acid. The microstructure characteristics under different aging times were observed by optical microscope (OM, Olympus Corporation, Tokyo, Japan). The ferrite contents in the OM images were quantitatively measured with ImageJ software (v.1.8.0, National Institutes of Health, Bethesda, Rockville, MD, USA). The error bars corresponding to the standard deviation were obtained by using the standard deviation function of the origin software. The microstructures before and after thermal aging were analyzed by a high-resolution transmission electron microscope (HRTEM, Tecnai G2 F20, FEI, Portland, OR, USA) operated at $200 \mathrm{KV}$. After the load-displacements of the SPT were terminated, the deformation and fracture surface morphology of the specimens were observed by scanning electron microscope (SEM, Carl Zeiss, Oberkochen, Germany).

\section{Results}

\subsection{Microstructural Evolution and Microhardness}

Figure 2a-e show the OM microstructure and morphology of the specimens under different thermal aging times. It can be seen that the island- and strip-shaped ferrites (gray $\delta$-phases) are uniformly distributed in the austenite matrix (bright $\gamma$-phases), and there is no significant difference in the microstructures of different aging times. It can be seen that the volume fraction of ferrite at different thermal aging times in the stainless steel is about $17 \%$ (Figure 2f). With the increase in thermal aging time, the ferrite content in the microstructure does not change significantly. The results show that thermal aging has basically no effect on the macrostructure and morphology of stainless steel.

In order to further study the effect of thermal aging on the ferrite phase of stainless steel, the ferrite phases in the microstructure are observed by TEM and HRTEM. Figure 3a shows the TEM and selected area electron diffraction (SAED) patterns of the unaged specimen (thermal aging for $0 \mathrm{~h}$ ). There is carbide precipitation along the $\delta / \gamma$ phase interface. Moreover, the corresponding ferrite diffraction pattern shows that there is no second phase in the ferrite. The HRTEM morphology in Figure $3 \mathrm{~b}$ and the corresponding fast Fourier transform (FFT) patterns further prove that there is no spinodal decomposition or phase precipitation in the unaged ferrite. Figure $3 \mathrm{c}$ is the result of the TEM 
observation of ferrite after $1000 \mathrm{~h}$ of thermal aging. It can be seen from the SAED that there is no obvious second phase inside the ferrite. HRTEM and the corresponding FFT patterns in Figure $3 \mathrm{~d}$ also confirm that no other second phase is precipitated in ferrite. However, it can be found that there are obvious "speckles" in the ferrite, which is a typical feature of spinodal decomposition according to previous reports $[13,21,23]$.
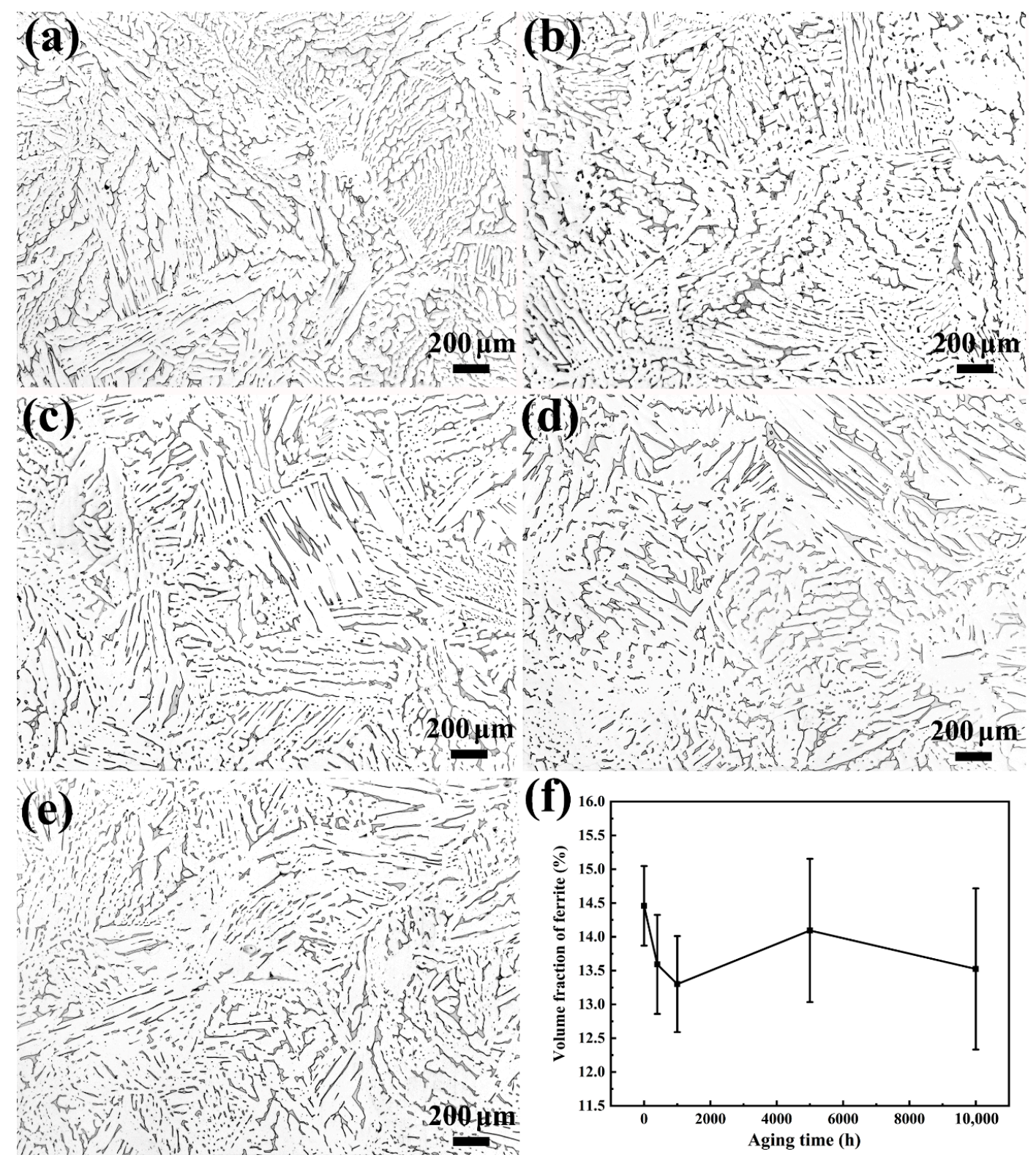

Figure 2. The metallographic microstructure and morphology of CDSS under the condition of thermal aging for (a) $0 \mathrm{~h}$, (b) $400 \mathrm{~h}$, (c) $1000 \mathrm{~h}$, (d) $5000 \mathrm{~h}$ and (e) 10,000 h; (f) the corresponding volume fractions of ferrite at different aging times.

Figure $4 \mathrm{a}, \mathrm{b}$ shows the TEM observation results of ferrites aged for $5000 \mathrm{~h}$. It can be seen from Figure 4a that there are obvious black second phase particles in ferrite, and the diffraction spots of the second phase appear in ferrite. The corresponding HRTEM shows the amplified morphology of the precipitates (Figure $4 \mathrm{~b}$ ). Combined with the results of previous literature [24,25], it can be determined that the black precipitates are G-phase. Figure $4 \mathrm{c}-\mathrm{f}$ shows the results of the TEM observation of the specimen after thermal aging for 10,000 h. The microstructure is shown in Figure 4c, and thermal aging has no significant effect on the macroscopic morphology of ferrite. The high-resolution morphology 
after thermal aging for 10,000 $\mathrm{h}$ is shown in Figure $4 \mathrm{~d}$. It can be seen that a large number of second phase particles appear in ferrite, which is significantly greater when compared to the thermal aging for $5000 \mathrm{~h}$. The SAED patterns of ferrite after thermal aging for 10,000 h are shown in Figure 4e. In addition to the diffraction spots of the ferrite phase of the body-centered cubic (BCC) structure, there is another set of G-phases of face-centered cubic (FCC) structures. The latter belongs to the (Fm-3m space group, 225) with the lattice parameter from 1.09 to $1.14 \mathrm{~nm}$, which is exactly four times that of ferrite. Compared with Figure $4 a$, it can be seen that the diffraction spots of the precipitated phase in ferrite after thermal aging for $10,000 \mathrm{~h}$ are more obvious, which indicates that the increase in thermal aging time promotes the growth of the precipitated phase in ferrite. Figure $4 \mathrm{f}$ shows the high-resolution morphology of the precipitates in the ferrite matrix and the corresponding FFT patterns. The average size of the precipitates is about $5 \mathrm{~nm}$, which is slightly larger than that after thermal aging for $5000 \mathrm{~h}$. Moreover, the existence of G-phase can be proved by FFT patterns. The corresponding inverse FFT patterns is shown in Figure $4 \mathrm{~g}$, and the interplanar distance of the (220) planes of the G-phase is about twice that of the (110) planes of the ferrite. There is a parallelism between planes and directions with the same crystallographic index. The relationships are consistent with those previously reported $[19,26]$ and can be described as:

$\{100\}_{\mathrm{F}} / /\{001\}_{\mathrm{G}}$

$\{110\}_{\mathrm{F}} / /\{110\}_{\mathrm{G}}$

$\{111\}_{\mathrm{F}} / /\{111\}_{\mathrm{G}}$

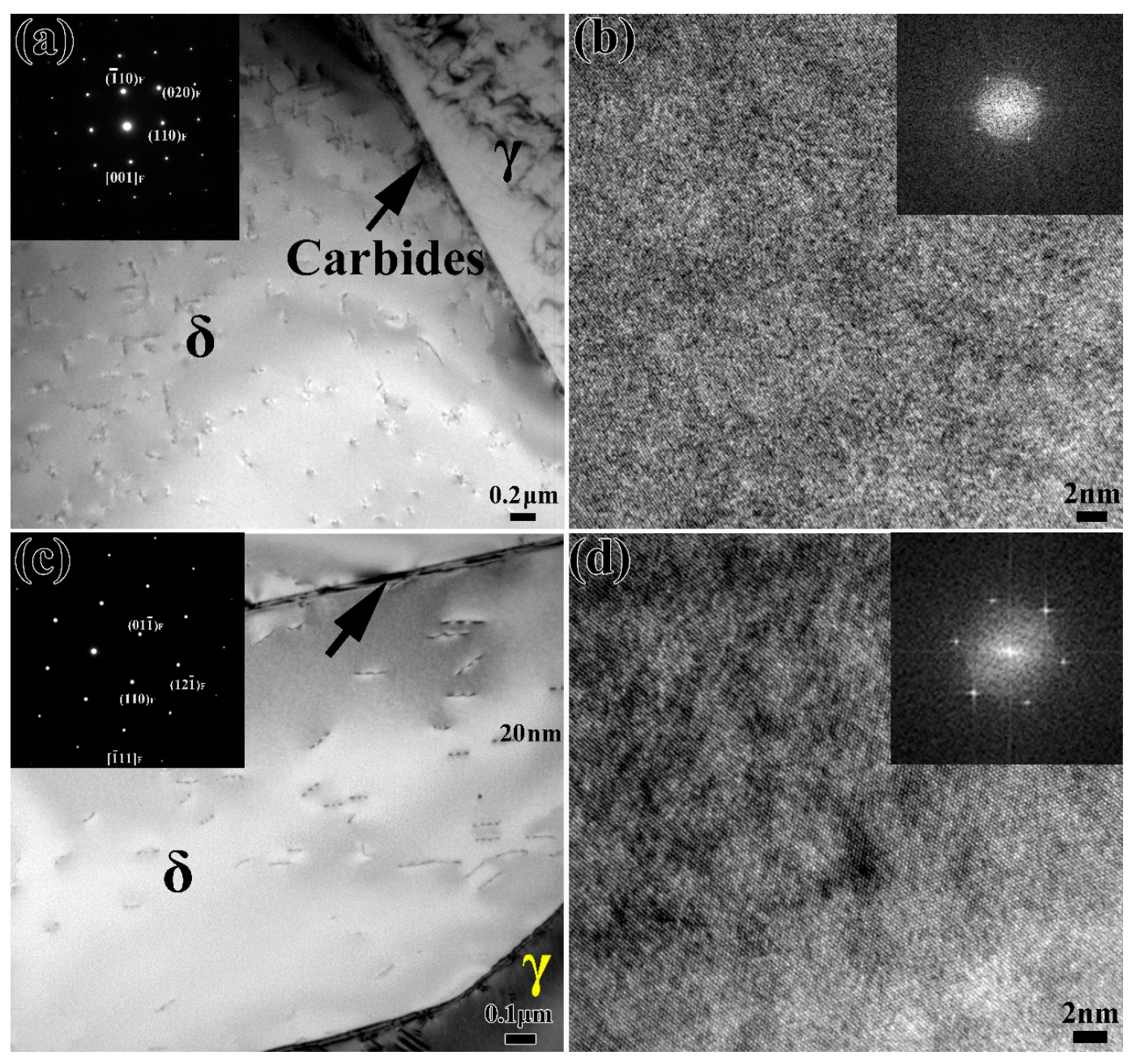

Figure 3. TEM and HRTEM images of stainless steel after aging for (a,b) $0 \mathrm{~h}$ and (c,d) $1000 \mathrm{~h}$; the corresponding SAED and FFT patterns are inserted. 

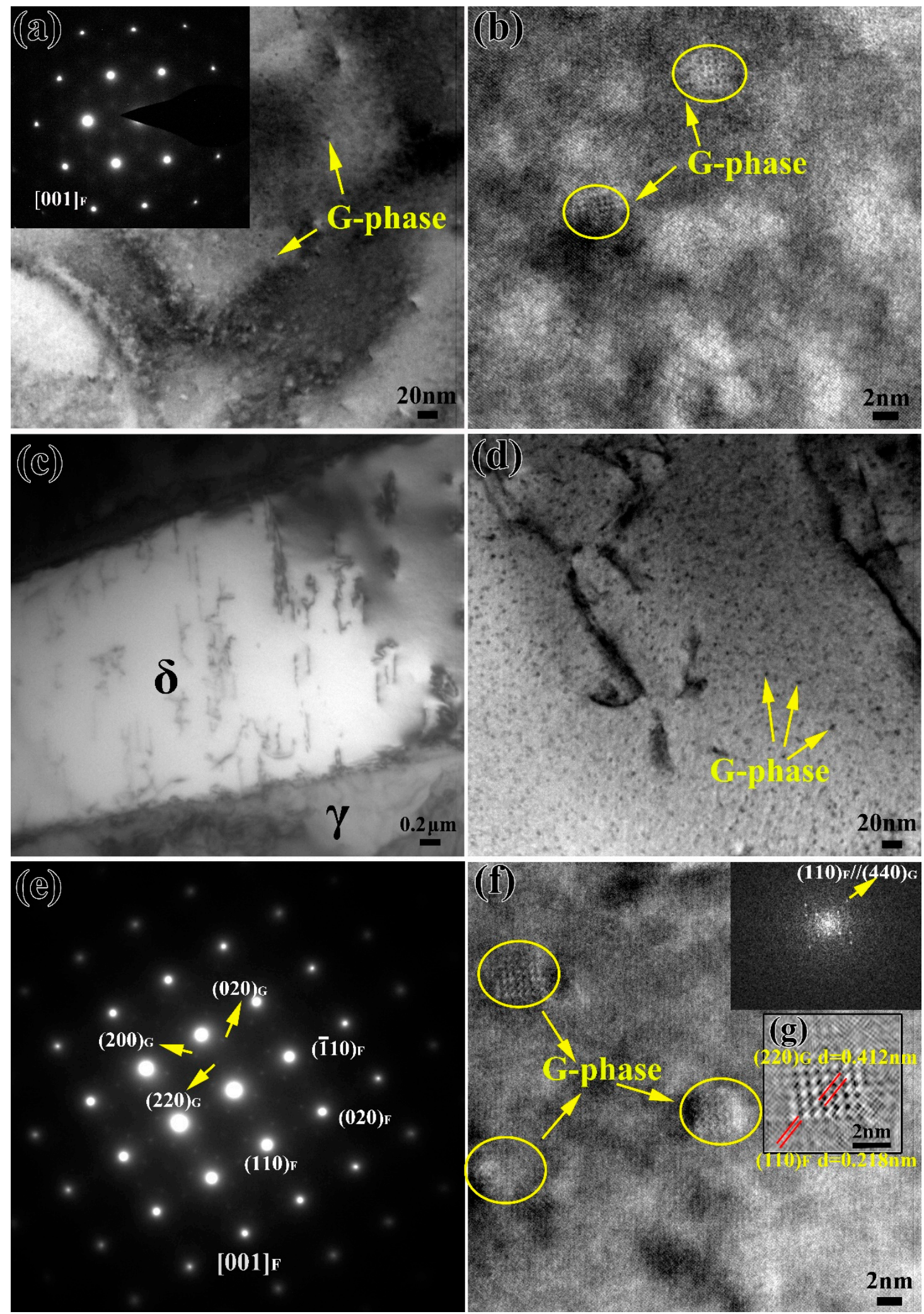

Figure 4. TEM and HRTEM images of stainless steel after aging for (a,b) $5000 \mathrm{~h}$ and (c-g) 10,000 h; the corresponding SAED, FFT and inverse FFT patterns are inserted.

The microhardness values of the ferrite and austenite phases under different thermal aging times are shown in Figure 5. It can be seen that the microhardness of the austenite phase has no obvious change with the extension of thermal aging time, but the microhardness of the ferrite phase increases 
significantly. In the early stage of thermal aging, the increase in microhardness is relatively fast, and the increase rate of microhardness decreases with the extension of the thermal aging time. There is an exponential relationship between the microhardness of the ferrite phase and the aging time. It can also be clearly seen from the microstructure that the area of the square indentation marks appearing in the ferrite aged for $5000 \mathrm{~h}$ is significantly reduced compared to that aged for $1000 \mathrm{~h}$ under the same loading force, while the austenite has basically no change. The results show that the microhardness change of ferrite during thermal aging is mainly caused by the transformation of the ferrite microstructure.

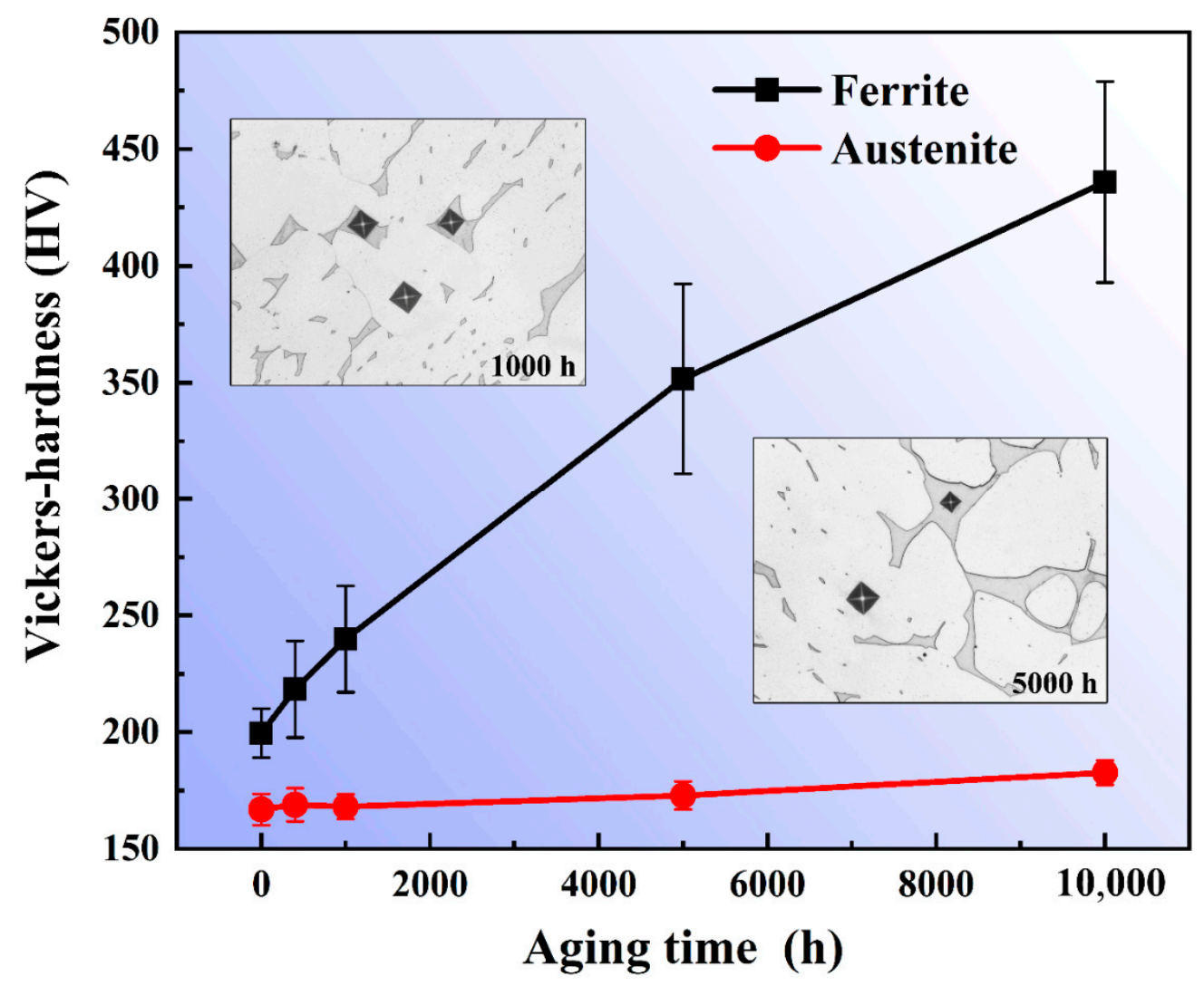

Figure 5. Microhardness of ferrite and austenite phases under different thermal aging time.

\subsection{Small Punch Test}

Figure 6a shows the load-displacement curves of the specimens under different thermal aging times. It can be seen that the load-displacement curves of the specimens under different thermal aging times are obviously different. Under the same displacement, as the thermal aging time increases, the required load gradually increases. In addition, the maximum displacement gradually decreased from $2.64 \mathrm{~mm}$ to about $2.38 \mathrm{~mm}$ with the increase in thermal aging time, which indicates that the specimen after thermal aging is more likely to produce fracture behavior at a lower displacement, thus leading to failure. The classification diagram of the load-displacement curve area of the unaged small punch specimen is shown in Figure $6 \mathrm{~b}$. The load-displacement curve can be divided into four parts according to the change of curve slope: (1) the elastic bending deformation zone $\left(W_{\mathrm{e}}\right)$, in which the elastic deformation occurs; (2) the plastic bending deformation zone $\left(W_{p}\right)$, in which the plastic deformation occurs; $(3)$ the membrane stretching zone $\left(\mathrm{W}_{\mathrm{m}}\right)$, in which the material further plastic deformation occurs and the material undergoes obvious elongation; (4) the instability fracture zone $\left(\mathrm{W}_{\mathrm{f}}\right)$, in which cracks appear in the small punch specimen, and the material has failed. We can see the load-displacement curves of the four zones with significantly different curvatures. In addition, the $W_{p}$ and $W_{f}$ are the main components of the load-displacement curve in the SPT. Therefore, the changes 
in the $W_{p}$ and $W_{m}$ of the small punch specimen, especially the $W_{m}$, dominate the changes in the mechanical properties of the material.
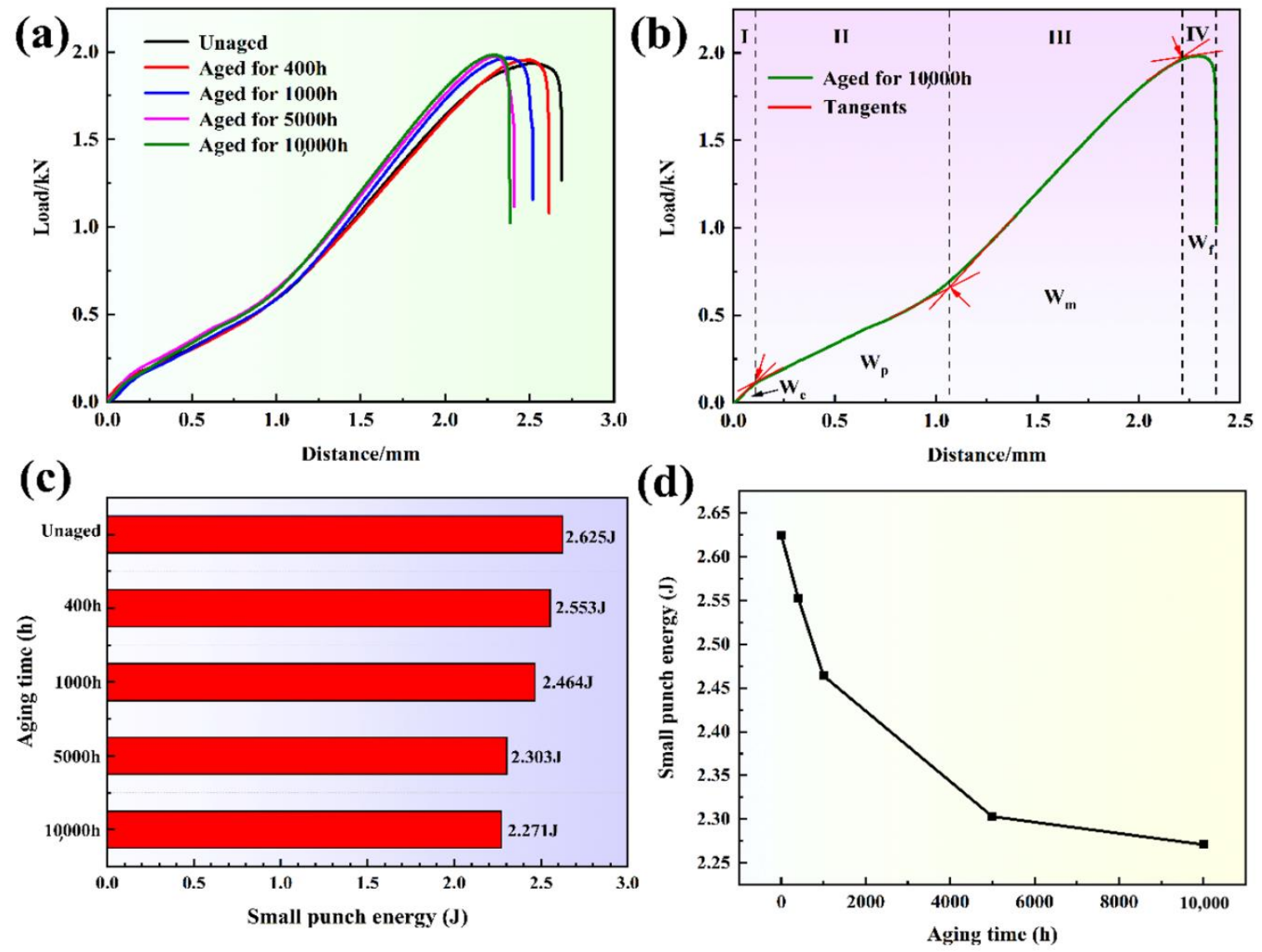

Figure 6. (a) The load-displacement curves of the specimens under different thermal aging times, (b) the classification diagram of the load-displacement curve area of the unaged small punch specimen, $(\mathbf{c}, \mathbf{d})$ the change chart of small punch energy with thermal aging time.

It is believed that the area enclosed by the load-displacement curve and the horizontal and vertical coordinates can be defined as the small punch energy, so the small punch energy results of the specimens under different thermal aging times are shown in Figure 6c. The small punch energy of the unaged specimen is $2.625 \mathrm{~J}$, while with the increases in thermal aging time, the small punch energy gradually decreases to $2.553,2.464,2.303$ and $2.271 \mathrm{~J}$. During thermal aging for $0-1000 \mathrm{~h}$, the energy of the small punch drops rapidly, and as the thermal aging time increases to $10,000 \mathrm{~h}$, the energy of the small punch gradually decreases (Figure 6d). Among the four parts (Figure 6b), the energy values of $W_{e}, W_{p}$ and $W_{f}$ change little with the thermal aging time, but the energy of $W_{m}$ changes obviously, which shows that the deformation behavior of the $W_{m}$ is the main reason for the brittleness of the CDSS.

In the SPT load-displacement curve, the change of $W_{m}$ plays an important role in the mechanical properties of stainless steel before and after thermal aging. Therefore, the differences in the deformation and fracture behavior in the $\mathrm{W}_{\mathrm{m}}$ of the specimens with different thermal aging times are analyzed. Figure 7 shows the SEM morphology of the specimens at the same displacement (displacement at $2.2 \mathrm{~mm}$, critical point of unaged $\mathrm{W}_{\mathrm{m}}$ and $\mathrm{W}_{\mathrm{f}}$ ) after thermal aging for $0 \mathrm{~h}$ and $10,000 \mathrm{~h}$. It can be seen that the specimen surface mainly includes two zones of $W_{\mathrm{p}}$ and $\mathrm{W}_{\mathrm{m}}$. In addition, the surface of the unaged specimen is still in a good plastic deformation state (Figure 7a), while the surface of the specimen has been wrinkled obviously after thermal aging for 10,000 $\mathrm{h}$, and microcracks appear in $\mathrm{W}_{\mathrm{m}}$, indicating that the plasticity of the specimen has decreased significantly. The SEM morphology of 
the $W_{m}$ unaged specimen is shown in Figure 7c. The ferrite and austenite phases show good plasticity and deformation coordination. The deformation in the austenite phase can smoothly drive the ferrite phase to carry on the deformation process. Therefore, the ferrite phase can generate continuous linear slip bands throughout the entire ferrite, which are also known as A2 type slip bands [27]. However, for thermal aging for 10,000 h (Figure 7d), the deformation coordination between austenite and ferrite phases is poor, and the ferrite phase can only pass through independent deformation. Therefore, some completely curved slip bands are generated inside the ferrite phase, which has no contact with the $\delta / \gamma$ phase interface and belongs to the slip bands produced by the independent deformation of ferrite, also known as F1 type slip bands [27]. Austenite and ferrite have different slip direction and deformation on both sides of the phase boundary. Most of the slip lines are blocked by the phase boundary, and gather at the phase boundary and change direction [28]. Microcracks initiate at the $\delta / \gamma$ phase interface and propagate to the ferrite phase.
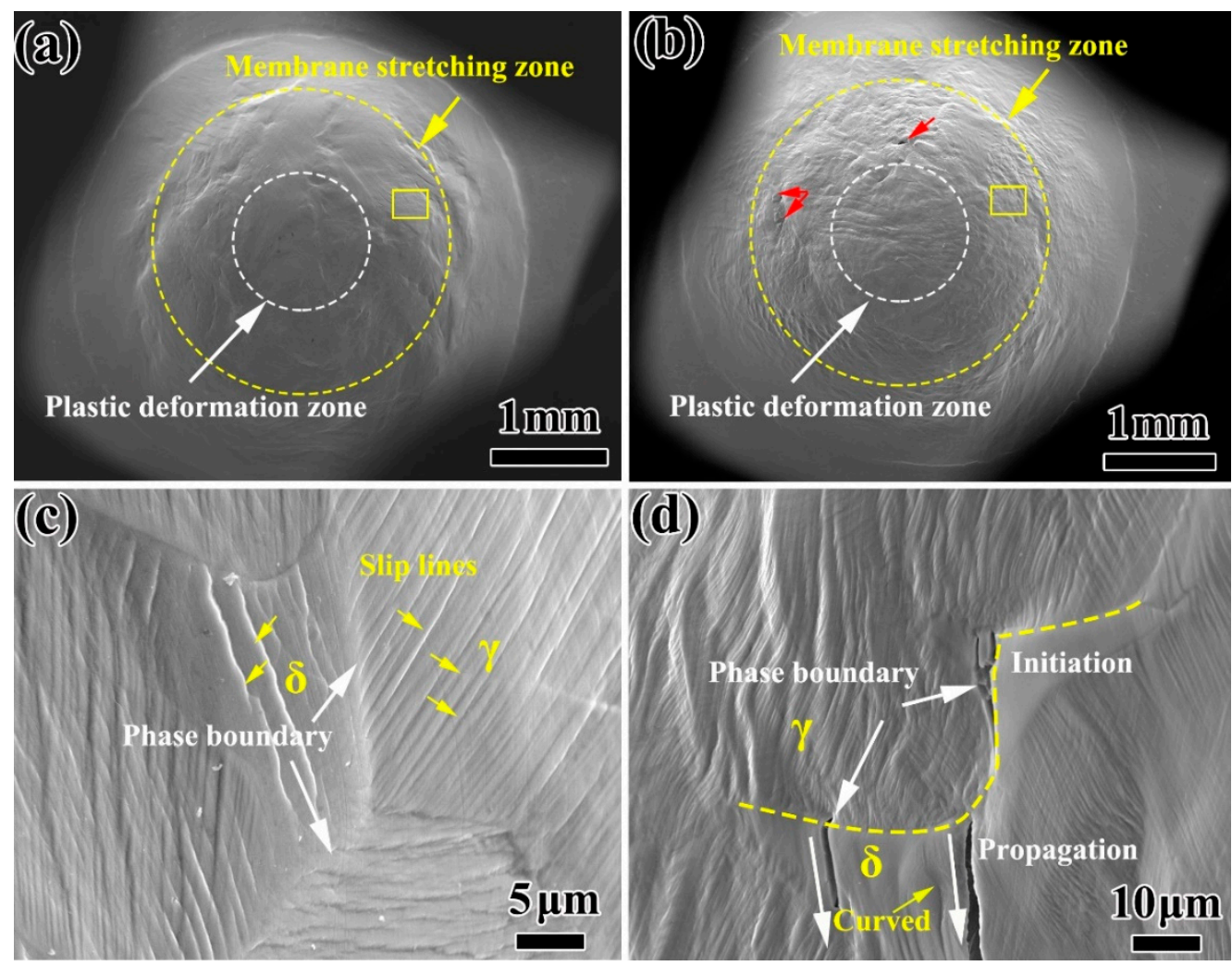

Figure 7. The overall SEM morphology of the small punch specimen after thermal aging for $0 \mathrm{~h}(\mathbf{a})$ and $10,000 \mathrm{~h}(\mathbf{b})$ at the same displacement; $(\mathbf{c}, \mathbf{d})$ are the SEM morphology of the corresponding position in the yellow box $(\mathbf{a}, \mathbf{b})$.

Figure 8a shows the SEM morphology of the small punch specimen after thermal aging for $400 \mathrm{~h}$. It can be seen that there is a circumferential crack on the surface of the specimen. Figure $8 \mathrm{c}$ is the SEM morphology at the white arrow in Figure 8a. The specimen has good plasticity and a large number of dimples on the fracture surface, which is mainly a ductile fracture. Figure $8 b$ shows the surface morphology of the small punch specimen after thermal aging for $5000 \mathrm{~h}$. Compared with the thermal aging of $400 \mathrm{~h}$, the thermal aging of $5000 \mathrm{~h}$ has a long circumferential crack and axial cracks on the surface of the specimen. Moreover, the impact depth and range of the specimen are obviously smaller than those of the thermal aging for $400 \mathrm{~h}$, indicating that the absorbed strain energy is less. By observing the fracture morphology at the white arrow (as shown in Figure 8d), it can be seen that the $5000 \mathrm{~h}$ aged specimen shows obvious brittleness characteristics. In addition to a few dimples, there are some quasi-cleavage phenomena in the fracture morphology of the specimen, and the edges 
of some areas were torn. The above results show that with the increase in thermal aging time to $5000 \mathrm{~h}$, the initial ductile fracture of stainless steel gradually changes to the mixed fracture mode of ductile fracture and quasi-cleavage.
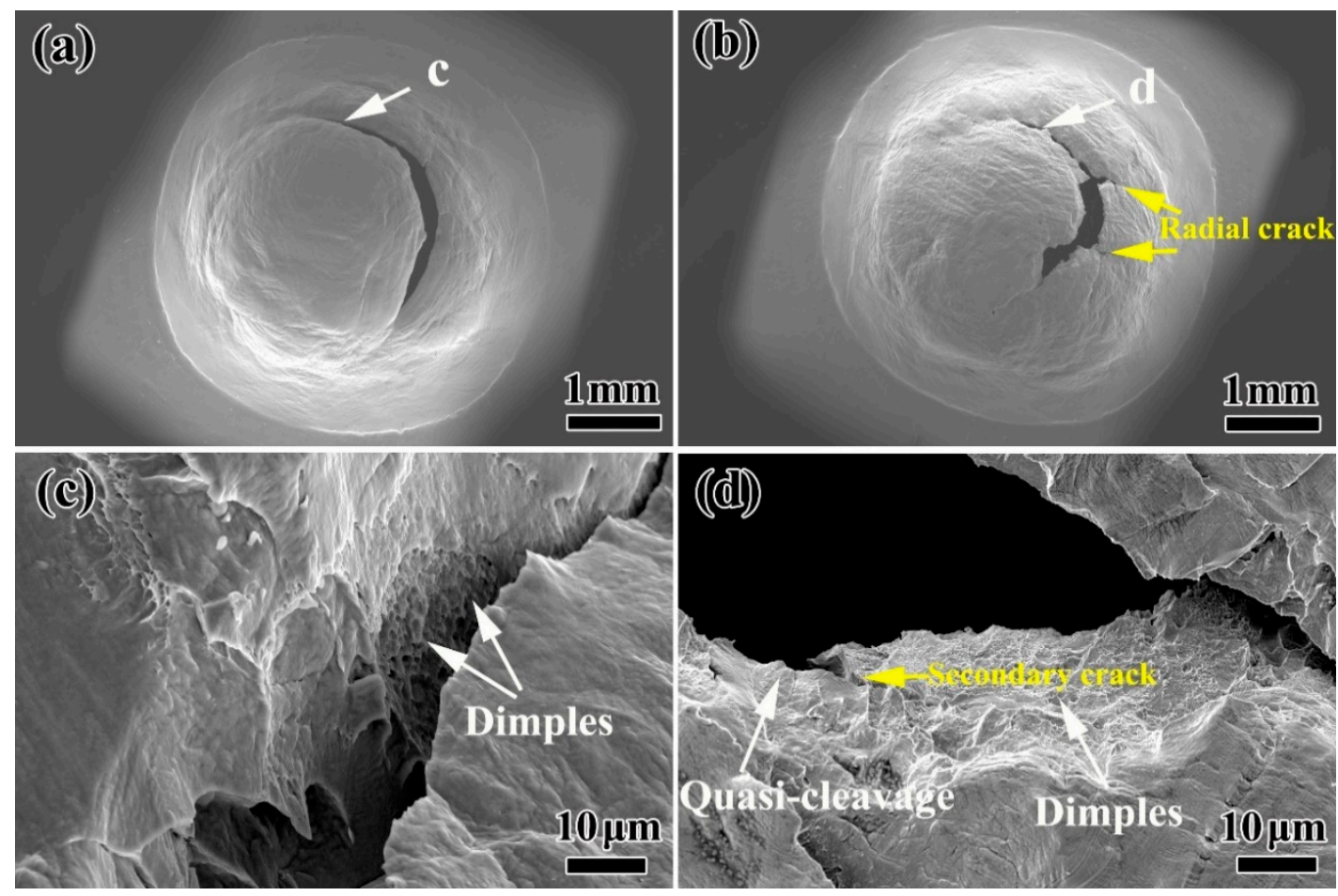

Figure 8. The overall SEM morphology of the small punch specimen after thermal aging for (a) $400 \mathrm{~h}$ and (b) $5000 \mathrm{~h}$ when the loading decreases by $80 \%$ of the maximum; (c,d) are the SEM morphologies of the corresponding positions in the white arrows $(\mathbf{a}, \mathbf{b})$.

\section{Discussion}

\subsection{Effect of Thermal Aging on Microstructure and Hardness}

In the binary alloy phase diagram, there was, generally, nucleation-growth metastable phase decomposition and spinodal decomposition of the unstable phase [29]. Therefore, the thermodynamic conditions of spinodal decomposition were such that a small component fluctuation could continuously reduce the free energy in the system, so that the inside of the ferrite phase could be decomposed spontaneously by uphill diffusion. During low-temperature thermal aging, spinodal decomposition occurred in the ferrite, in which the spinodal was approximately uniformly decomposed into the Fe-rich $\alpha$ phase and Cr-rich $\alpha^{\prime}$ phase [14,15], while austenite remains basically unchanged. The spinodal decomposition occurred at the beginning of the thermal aging process, and the degree of decomposition increased with the increase in thermal aging time (Figures 3 and 4). For the formation process of the G-phase, it could be divided into two steps: (1) when $\alpha$ phase and $\alpha^{\prime}$ phase were formed by spinodal decomposition, the forming elements ( $\mathrm{Si}, \mathrm{Ni}, \mathrm{Mn}$ and $\mathrm{Mo}$, etc.) of $\mathrm{G}$-phase were excluded to the interface; (2) when the chemical composition at the interface reached a certain critical value, G-phase began to nucleate and grow [12,13]. The formation of G-phase in ferrite needed a certain incubation period. For different materials, the incubation period was different. The unified statement was that the obvious G-phase would be precipitated after $3000 \mathrm{~h}$ of thermal aging. Moreover, the formation of G-phase was not observed at $1000 \mathrm{~h}$ of thermal aging in cast duplex stainless steel (Figure 3), and the obvious precipitation of G-phase was observed at $5000 \mathrm{~h}$ of thermal aging (Figure 4). Therefore, it could be inferred that the precipitation of G-phase should occur at 1000-5000 h of thermal aging in cast duplex stainless steel. The transformation of the ferrite microstructure during thermal aging directly led to 
the hardening of ferrite. The elastic stress and strain field caused by the lattice mismatch between the $\alpha$ and $\alpha^{\prime}$ phases generated by spinodal decomposition hinder dislocation movement and plastic deformation, thereby increasing the ferrite hardness [16,30].

\subsection{Effect of Thermal Aging on Mechanical Behavior}

The plastic deformation and rapid decrease in energy in $\mathrm{W}_{\mathrm{m}}$ (Figure 6) indicated that the plasticity decrease in the CDSS material after thermal aging was the main reason for thermal aging embrittlement. Figure 9 shows the crack initiation and propagation mechanisms of 'unaged' and 'aging for 10,000 h'. Both the ferrite and austenite phases had better plasticity before the thermal aging, and the material as a whole formed continuous and dense linear slip bands, and these slip lines can pass through the ferrite phase easily, so that the fracture morphology also shows uniformly distributed dimples. However, for the material after thermal aging for 10,000 $\mathrm{h}$, the continuous hardening of ferrite resulted in the increase in deformation incongruity between the ferrite and austenite phases and the concentration of stress at the $\delta / \gamma$ phase interface. Meanwhile, a large number of stacking faults in ferrite and the existence of lattice mismatch led to the formation of F1 type slip bands in ferrite phase. The combined effect of the curved slip bands and stress concentration eventually led to the initiation of obvious micro-cracks at the $\delta / \gamma$ phase interface. The micro-cracks propagated along the ferrite phase curved slip band and eventually penetrated the entire hardened ferrite phase. In terms of macroscopic morphology, it led to the appearance of axial cracks and the generation of mixed fracture modes at the fracture (Figure 8).

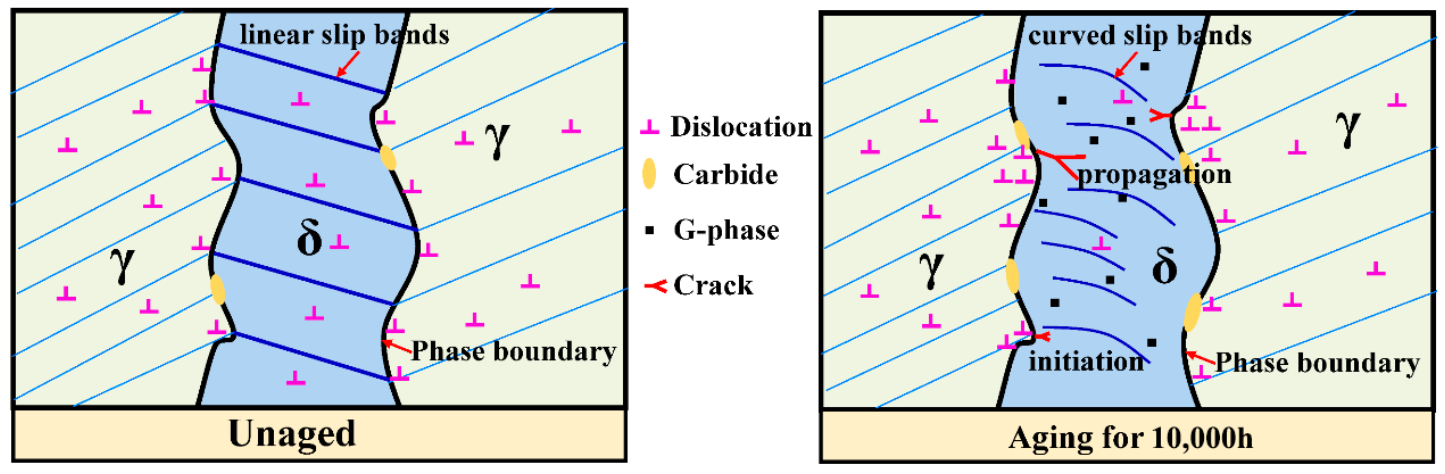

Figure 9. The crack initiation and propagation mechanism of CDSS.

In addition, the decrease in small punch energy was mainly divided into two stages. During $1000 \mathrm{~h}$ of thermal aging, the decreases in small punch energy were relatively rapid. With the increase in thermal aging time to $10,000 \mathrm{~h}$, the energy of small punch decreased slowly (Figure 8). Combined with previous studies on the microstructure change, only the existence of spinodal decomposition was found in the specimen aged for $0-1000 \mathrm{~h}$, which indicated that the rapid decrease in small punch energy after thermal aging for $0-1000 \mathrm{~h}$ was caused by spinodal decomposition. However, with the increase in aging time, the G-phase appeared in the ferrite phase, indicating that the small punch energy was slowly reduced by the combined effect of spinodal decomposition and precipitates. The formation of a large number of G-phases during thermal aging would lead to the lack of $\mathrm{Ni}$ in the ferrite matrix, which in turn slowed the rate of spinodal decomposition, thereby reducing the embrittlement sensitivity of the material to a certain extent [16].

\section{Conclusions}

The microstructural evolution and microhardness properties of CDSS during thermal aging at $400{ }^{\circ} \mathrm{C}$ were investigated. Moreover, the deformation behavior and fracture mechanism of CDSS before and after thermal aging were characterized and analyzed by means of SPT. The major results can be drawn as follows: 
(1) The thermal aging time of ferrite in CDSS began to precipitate the G-phase between 1000 and $5000 \mathrm{~h}$, and the growth of G-phase in ferrite was promoted with the increase in aging time;

(2) During the deformation process of $\mathrm{W}_{\mathrm{m}}$ in the SPT, the unaged ferrite phase could generate continuous linear slip bands throughout the entire ferrite. However, for thermal aging for 10,000 $\mathrm{h}$, some completely curved slip bands were generated inside the ferrite phase, which had no contact with the $\delta / \gamma$ phase interface and belonged to the slip bands produced by the independent deformation of ferrite;

(3) The combined effect of the curved slip bands and stress concentration led to the initiation of obvious micro-cracks at the $\delta / \gamma$ phase interface. The micro-cracks propagated along the ferrite phase curved slip bands and eventually penetrated the entire hardened ferrite phase.

Author Contributions: Conceptualization, Z.L. and Y.H.; methodology, Z.L. and Y.H.; investigation, Y.H., X.W., and T.C.; data curation, X.W.; writing-original draft preparation, Z.L.; writing-review and editing, Y.L.; supervision, Y.L. and P.L.; project administration, T.C. and P.L.; funding acquisition, T.C. and P.L. All authors have read and agreed to the published version of the manuscript.

Funding: The authors acknowledge the financial supports from the State Key Laboratory of Nuclear Power Safety Monitoring Technology and Equipment (K-A2018.419).

Conflicts of Interest: The authors declare no conflict of interest.

\section{References}

1. Xue, F.; Wang, Z.X.; Shu, G.G.; Yu, W.W.; Shi, H.J.; Ti, W.X. Thermal aging effect on Z3CN20.09M cast duplex stainless steel. Nucl. Eng. Des. 2009, 239, 2217-2223. [CrossRef]

2. Chen, S.; Miyahara, Y.; Nomoto, A.; Nishida, K. Effects of thermal aging and low-fluence neutron irradiation on the mechanical property and microstructure of ferrite in cast austenitic stainless steels. Acta Mater. 2019, 179, 61-69. [CrossRef]

3. Guo, E.Y.; Xie, H.X.; Singh, S.S.; Kirubanandham, A.; Jing, T.; Chawla, N. Mechanical characterization of microconstituents in a cast duplex stainless steel by micropillar compression. Mater. Sci. Eng. A 2014, 598, 98-105. [CrossRef]

4. Zhang, B.; Xue, F.; Li, S.L.; Wang, X.T.; Liang, N.N.; Zhao, Y.H.; Sha, G. Non-uniform phase separation in ferrite of a duplex stainless steel. Acta Mater. 2017, 140, 388-397. [CrossRef]

5. Landowski, M.; Świerczyńska, A.; Rogalski, G.; Fydrych, D. Autogenous Fiber Laser Welding of 316L Austenitic and 2304 Lean Duplex Stainless Steels. Materials 2020, 13, 2930. [CrossRef]

6. Badyka, R.; Monnet, G.; Saillet, S.; Domain, C.; Pareige, C. Quantification of hardening contribution of G-Phase precipitation and spinodal decomposition in aged duplex stainless steel: APT analysis and micro-hardness measurements. J. Nucl. Mater. 2019, 514, 266-275. [CrossRef]

7. Lach, T.G.; Frazier, W.E.; Wang, J.; Devaraj, A.; Byun, T.S. Precipitation-site competition in duplex stainless steels: $\mathrm{Cu}$ clusters vs spinodal decomposition interfaces as nucleation sites during thermal aging. Acta Mater. 2020, 196, 456-469. [CrossRef]

8. Frazier, W.E.; Lach, T.G.; Byun, T.S. Monte Carlo simulations of $\mathrm{Cu} / \mathrm{Ni}-\mathrm{Si}-\mathrm{Mn}$ co-precipitation in duplex stainless steels. Acta Mater. 2020, 194, 1-12. [CrossRef]

9. Zhang, Q.; Ma, S.; Jing, T. Mechanical Properties of a Thermally-aged Cast Duplex Stainless Steel by in Situ Tensile Test at the Service Temperature. Metals 2019, 9, 317. [CrossRef]

10. Cao, X.; Zhu, P.; Wang, W.; Liu, T.; Lu, Y.; Shoji, T. Precipitation behavior of stainless steel weld overlay cladding exposed to a long-term thermal aging. Mater. Charact. 2018, 137, 77-83. [CrossRef]

11. Zhang, Q.; Singaravelu, A.S.S.; Zhao, Y.; Jing, T.; Chawla, N. Mechanical properties of a thermally-aged cast duplex stainless steel by nanoindentation and micropillar compression. Mater. Sci. Eng. A 2019, 743, 520-528. [CrossRef]

12. Jacob, A.; Domain, C.; Adjanor, G.; Todeschini, P.; Povoden-Karadeniz, E. Thermodynamic modeling of G-phase and assessment of phase stabilities in reactor pressure vessel steels and cast duplex stainless steels. J. Nucl. Mater. 2020, 533, 152091. [CrossRef]

13. Mateo, A.; Llanes, L.; Anglada, M.; Redjaimia, A.; Metauer, G. Characterization of the intermetallic G-phase in an AISI 329 duplex stainless steel. J. Mater. Sci. 1997, 32, 4533-4540. [CrossRef] 
14. Chen, Y.; Dai, X.; Chen, X.; Yang, B. The characterization of G-phase in Fe20Cr9Ni cast duplex stainless steel. Mater. Charact. 2019, 149, 74-81. [CrossRef]

15. Li, S.; Wang, Y.; Zhang, H.; Zheng, K.; Xue, F.; Wang, X. Microstructure evolution and impact fracture behaviors of Z3CN20-09M stainless steels after long-term thermal aging. J. Nucl. Mater. 2013, 433, 41-49. [CrossRef]

16. Chandra, K.; Kain, V.; Bhutani, V.; Raja, V.S.; Tewari, R.; Dey, G.; Chakravartty, J. Low temperature thermal aging of austenitic stainless steel welds: Kinetics and effects on mechanical properties. Mater. Sci. Eng. A 2012, 534, 163-175. [CrossRef]

17. Li, Y.-S.; Li, S.-X.; Zhang, T.-Y. Effect of dislocations on spinodal decomposition in Fe-Cr alloys. J. Nucl. Mater. 2009, 395, 120-130. [CrossRef]

18. Pareige, C.; Emo, J.; Saillet, S.; Domain, C. Kinetics of G-phase precipitation and spinodal decomposition in very long aged ferrite of a Mo-free duplex stainless steel. J. Nucl. Mater. 2015, 465, 383-389. [CrossRef]

19. Tucker, J.D.; Miller, M.; Young, G. Assessment of thermal embrittlement in duplex stainless steels 2003 and 2205 for nuclear power applications. Acta Mater. 2015, 87, 15-24. [CrossRef]

20. Hilders, O.; Zambrano, N. The effect of aging on impact toughness and fracture surface fractal dimension in SAF 2507 super duplex stainless steel. J. Microsc. Ultrastruct. 2014, 2, 236-244. [CrossRef]

21. Cao, X.; Zhu, P.; Liu, T.; Lu, Y.; Shoji, T. Thermal aging effects on mechanical and electrochemical properties of stainless steel weld overlay cladding. Surf. Coat. Technol. 2018, 344, 111-120. [CrossRef]

22. McNaught, A.D.; Wilkinson, A. (Eds.) IUPAC Compendium of Chemical Terminology, 2nd ed.; Blackwell Scientific Publications: Oxford, UK, 1997.

23. Albuquerque, V.H.C.; Silva, E.D.M.; Leite, J.P.; Moura, E.P.; Freitas, V.L.D.A.; Tavares, J.M.R.S. Spinodal decomposition mechanism study on the duplex stainless steel UNS S31803 using ultrasonic speed measurements. Mater. Des. 2010, 31, 2147-2150. [CrossRef]

24. Li, S.; Wang, Y.; Wang, X.; Xue, F. G-phase precipitation in duplex stainless steels after long-term thermal aging: A high-resolution transmission electron microscopy study. J. Nucl. Mater. 2014, 452, 382-388. [CrossRef]

25. Chen, W.-Y.; Li, M.; Zhang, X.; Kirk, M.A.; Baldo, P.M.; Lian, T. In situ TEM study of G-phase precipitates under heavy ion irradiation in CF8 cast austenitic stainless steel. J. Nucl. Mater. 2015, 464, 185-192. [CrossRef]

26. Matsukawa, Y.; Takeuchi, T.; Kakubo, Y.; Suzudo, T.; Watanabe, H.; Abe, H.; Toyama, T.; Nagai, Y. The two-step nucleation of G-phase in ferrite. Acta Mater. 2016, 116, 104-113. [CrossRef]

27. Serre, I.; Salazar, D.; Vogt, J.-B. Atomic force microscopy investigation of surface relief in individual phases of deformed duplex stainless steel. Mater. Sci. Eng. A 2008, 492, 428-433. [CrossRef]

28. Li, Z.; Wang, X.; Chen, T.; Feng, F.; Liu, P.; Lu, Y. Experimental and Numerical Evaluation on Deformation and Fracture Mechanism of Cast Duplex Stainless Steel Tubular Specimen. Materials 2020, 13, 3430. [CrossRef]

29. John, W.C. On spinodal decomposition Sur la decomposition spinodale Über die umsetzung an der spinodalen. Acta Metall. 1961, 9, 795-801.

30. Danoix, F.; Auger, P. Atom Probe Studies of the Fe-Cr System and Stainless Steels Aged at Intermediate Temperature. Mater. Charact. 2000, 44, 177-201. [CrossRef]

Publisher's Note: MDPI stays neutral with regard to jurisdictional claims in published maps and institutional affiliations.

(C) 2020 by the authors. Licensee MDPI, Basel, Switzerland. This article is an open access article distributed under the terms and conditions of the Creative Commons Attribution (CC BY) license (http://creativecommons.org/licenses/by/4.0/). 